\title{
Diagnosing the Organizational Culture of Higher Education Libraries in the United Arab Emirates Using the Competing Values Framework
}

\author{
Kumaresan Chidambaranathan \\ Academic Bridge Program, \\ Qatar Foundation, Doha, Qatar \\ sckumaresan@yahoo.com \\ V. Sakthi Regha \\ The Madras School of Social Work, Chennai, India \\ vsakthirekha@yahoo.com
}

\begin{abstract}
Background. Organizational culture is an important ingredient of organizational success and employee performance. This study used the Competing Values Framework (CVF) to analyze the organizational culture types exhibited and the preferred culture in higher education libraries in the United Arab Emirates (UAE). The framework analyzes the dominant culture based on four culture types: Clan, Adhocracy, Market and Hierarchy.

Objectives. The study sought to identify the current culture and the preferred culture of employees of higher education libraries in the UAE, and to compare the culture profiles of public versus privately-funded libraries as well as the average culture profiles of libraries across all the Emirates.

Method. A sample of 355 employees were selected from all 40 higher education libraries in the UAE. An online questionnaire containing the Organizational Culture Assessment Instrument was used to obtain responses from the employees about their perception of the existing and preferred culture. 263 responses from 39 higher education libraries were returned usable at a return rate of $74 \%$.

Results. The findings indicate that Clan and Adhocracy cultures are the dominant culture types prevailing in the higher education libraries in the UAE. However, the employees prefer greater Clan and Adhocracy cultures, and very low market and hierarchy cultures in their libraries. The results for the public and private universities, and the average culture profile in each of the Emirates are also presented.
\end{abstract}

\section{INTRODUCTION}

Culture can be considered as the pattern of norms, values, beliefs and attitudes that influence behavior within an organization (Schein, 1985). Organizational culture stems from an enduring set of values, beliefs, attitudes and assumptions that characterize organizations and its employees. Ravasi and Schultz (2006) defined organizational culture as "a set of shared mental assumptions that guide interpretation and action in organizations by defining 
appropriate behavior for different situations” (p. 435). They also further stated that, although an organization may have a unique culture of its own, sub-cultures that are different and conflicting may exist within a large organization.

These values and attitudes affect organizational effectiveness, and have a strong influence on the decision-making process in an organization. This study identifies the current culture types in higher education libraries in the United Arab Emirates (UAE) and the "preferred" culture of the employees in these libraries. Hence, its results can help library managers to understand the cultural profile of their library and the country. It can also help to identify what and how sustainable business practices can be implemented in libraries with particular culture profiles.

Higher education in the UAE is driven by public and private universities established by both the government of the UAE and foreign universities through their branch campuses. UAE is one of those countries in the Middle East where a large population of expatriates from around the world live and work. Changes in organizational culture affect organizational effectiveness. With large numbers of expatriates in the higher education libraries, cultural transformation takes place when people leave or take up jobs, which in turn affects organizational effectiveness. Understanding the relationship between culture, employee attitudes, and behaviors is crucial to maintaining and improving organizational effectiveness. If the findings reveal that organizational effectiveness varies in specific aspects between organizational cultures, then library directors and administrators can strengthen these aspects or take strategic decisions to change to the desired culture type. Hence, this study was undertaken to understand the prevailing culture and the preferred culture types in higher education libraries in the UAE.

\section{The Competing Values Framework}

The Competing Values Framework (CVF) was developed by Robert E. Quinn and John Rohrbaugh in1983 for assessing organizational culture. It has been quite popular among researchers for diagnosing and understanding a broad range of organizational phenomena. Cameron and Quinn (2006) proposed two major dimensions that categorize organizational culture into four clusters. According to them, "One of the dimensions differentiates effectiveness criteria that emphasize flexibility, discretion and dynamism from stability, order and control and the second dimension differentiates the effectiveness criteria that lays emphasis on an internal orientation, integration and unity from criteria that emphasize an external orientation, differentiation and rivalry” (Cameron \& Quinn, 2011, p. 130).

Accordingly, these two dimensions together form four quadrants, each representing a distinct set of organizational effectiveness indicators. These indicators represent what people value about the organization's performance, and define what is seen as good and relevant. In other words, these four clusters of criteria define the core values on which judgments about organizations can be made (Cameron \& Quinn, 2011).

The upper left quadrant (see Figure 1) distinguishes values that emphasize internal focus, while the lower right quadrant distinguishes values that emphasize external, control focus. Similarly, the upper right quadrant identifies values that emphasize an external, organic focus and the lower left quadrant emphasizes internal, control values. It was because of these competing or opposite values in each quadrant that the name Competing Values Framework was given to the model (Cameron \& Quinn, 2011).

Each quadrant has been labeled as Clan, Adhocracy, Market and Hierarchy, based on extensive research that is derived from scholarly literature. According to Cameron and Quinn 


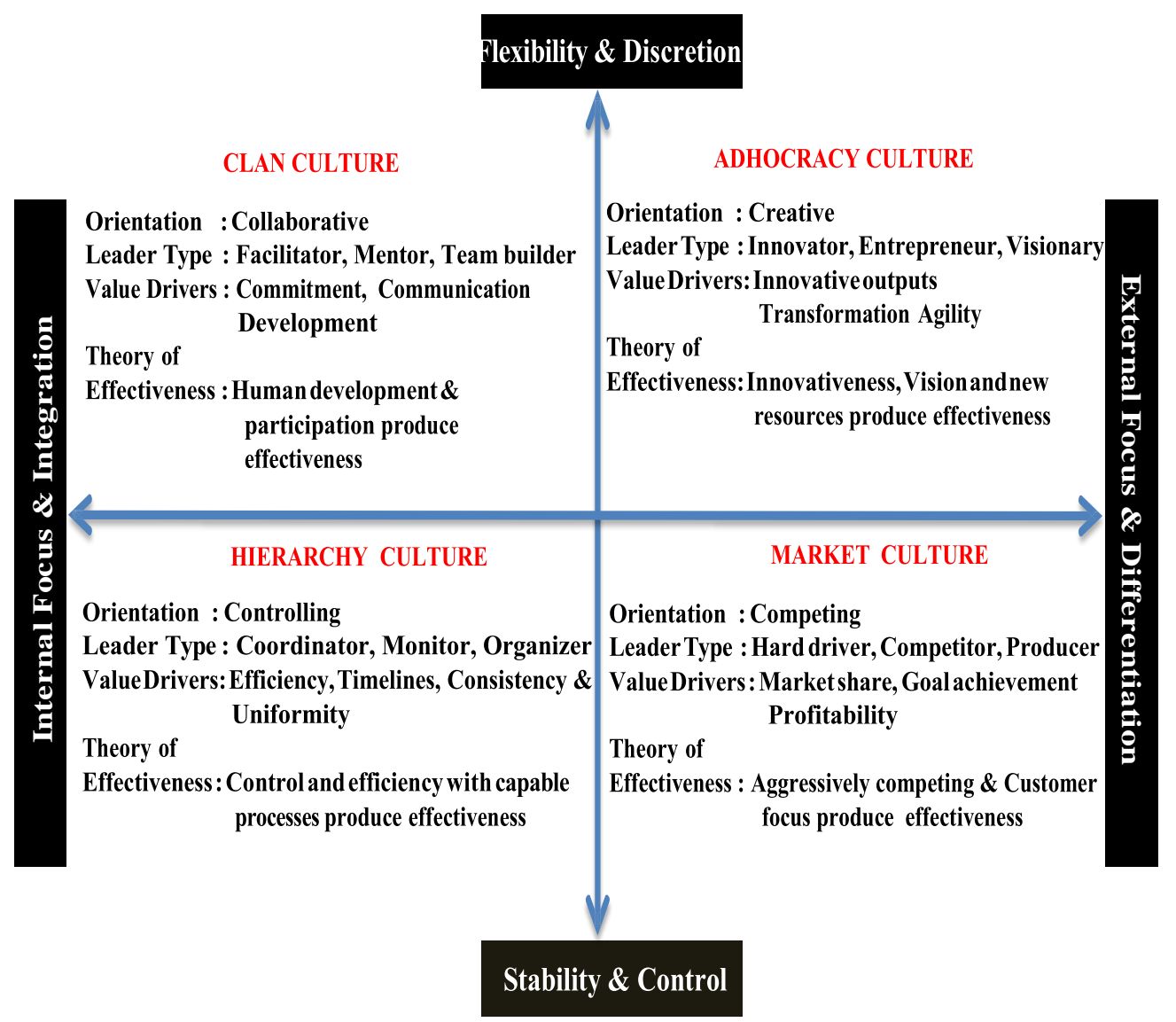

Figure 1. Competing Values Framework (adapted from Cameron \& Quinn, 2011)

(2011), the dimensions and quadrants are quite powerful in analyzing and clarifying the different orientations, and the competing values that characterize human behavior. The robustness of these dimensions and the richness of the resulting quadrants led them to identify each quadrant as a cultural type.

\section{Attributes of the Culture Types}

Cameron and Quinn (2011) describe each of these culture types as follows:

- Clan culture (internal focus and flexible) - A very friendly place of work where people share a lot of themselves. It is like an extended family, and the leaders or heads of the organization acts as mentors and parent figures. The organization is bound by loyalty or tradition, and its employees are highly committed. The organization's key focus is the long-term benefits of human resources. It attaches great importance to cohesion and morale. Success in these organizations is defined in terms of customer satisfaction and concern for the employees. The organizations give importance to teamwork, participation and consensus.

- Adhocracy culture (external focus and flexible) - A dynamic, entrepreneurial and creative place of work where people take risks. The heads are considered to be innovators and risk takers, and the organization sticks together based on the commitment to experimentation and innovation. The primary emphasis is on the leading edge, and the long-term emphasis is on growth and acquiring new resources. Success is defined in terms of developing 
unique and new products or services, and being a leader in the industry. The organization encourages individual initiative and freedom.

- Market culture (external focus and control) - A result-oriented organization where the major concern is getting the job done. People are competitive and goal oriented, and the leaders are hard drivers, producers and competitors. They are tough and demanding, and the glue that holds the organization together is an emphasis on winning. Reputation and success are common concerns. However, the long-term focus is on competitive actions and achievement of measurable goals and targets. Success is defined in terms of market share and penetration. Competitive pricing and market leadership are important. The organizational style is hard-driving competitiveness (Cameron \& Quinn, 2011).

- Hierarchy culture (internal focus and control) - A very formalized and structured place of work where formal procedures dictate what people do. Leaders in these organizations take pride in being skilful coordinators and efficient organizers. Maintaining the smooth functioning of the organization is the most critical factor for them. The glue that holds the organization is the formal rules and policies, and the long-term concern is on stability and efficient performance. Success is often defined in terms of dependable delivery, smooth scheduling and cost-effectiveness. The management of employees is concerned with secure employment and predictability (Cameron \& Quinn, 2011).

\section{Organizational Culture Assessment Instrument}

The Organizational Culture Assessment Instrument (OCAI) is a tool for diagnosing the organizational culture type, strength, and congruence, based on the principles of CVF. According to Cameron and Quinn (2011), the OCAI includes six cultural subsystems:

1. Dominant characteristics - that identifies whether an organization is i) a very personal place like a family, ii) entrepreneurial and risk taking, iii) competitive and achievement oriented, or iv) controlled and structured.

2. Leadership style - that can be identified as i) mentoring, facilitating, or nurturing, ii) entrepreneurial, innovative, or risk taking, iii) no-nonsense, aggressive, results oriented, or iv) coordinating, organizing, efficiency-oriented.

3. Management of employees - which emphasizes i) teamwork, consensus, and participation, ii) individual risk taking, innovation, freedom, and uniqueness, iii) competitiveness and achievement, or iv) security, conformity, predictability.

4. Organizational glue - that keeps the organization together are i) loyalty and mutual trust, ii) a commitment to innovation and development, iii) emphasis on achievement and goal accomplishment, or iv) formal rules and policies.

5. Strategic emphasis - which emphasizes i) human development, high trust, openness, ii) acquisition of resources and creation of new challenges, iii) competitiveness and winning, or iv) permanence and stability.

6. Criteria for success - defined as i) development of human resources, teamwork, and concern for people, ii) offering new and unique products and services, iii) winning in the marketplace and outpacing the competition, or iv) being dependable, efficient, and lowcost.

\section{LITERATURE REVIEW - ORGANIZATIONAL CULTURE AND LIBRARIES}

Organizational culture has been the subject of research for several decades, and much of our knowledge about it comes from the anthropological, sociological and socio-psychological fields (Durkheim, 1901/2014; Festinger, 1957; Geertz, 1973; Goodenough, 1971; 
Kamenskaya, 2010). Several theories and models have been proposed to study the organizational culture of organizations and how it affects effectiveness. Many authors agree that when an organization becomes ineffective, the culture should be diagnosed so as to bring about positive changes (Cameron \& Quinn, 2006; Grant \& Michelson, 2005). Kaarst-Brown, Nicholson, Von Dran and Stanton (2004) suggested that there is a clear link between the characteristics of organizational culture and improved effectiveness, especially among information organizations such as libraries. Panda and Mandal (2006) traced the changes in some library cultures around the world, and asserted that libraries have to modify a corporate culture to promote knowledge-based business and make their services customer -friendly. Lakos and Phipps (2004) stated that libraries had to assess their performance from the customer's point of view, and their employees should understand what is involved in the organizational culture. They also noted that transforming the library to reflect a culture of assessment is essential for customer satisfaction. Oberg (2009) talked about the integrated school library program and the need to understand and apply the concepts of culture and change in order to continuously improve the working environment. Linn (2008) stated that in advancing a library's issues, it is helpful for library directors to determine whether or not the organization's culture will support the measures proposed to implement the plans. She further concluded that although organizational culture might seem unimportant, it was an essential factor to consider during decision making, as it could make a huge difference.

The Competing Values Framework has been used widely as a popular tool to understand the organizational culture of various organizations for the past 25 years. Porumbeanu (2010) conducted a study to find out the elements that characterize the organizational culture in the library, in order to successfully implement knowledge management. The study was conducted in five university libraries in Romania, and the results showed that $89 \%$ of the respondents expressed their willingness to share pertinent knowledge. Among the reasons given for sharing are teamwork (18\%), exchange of experience (12\%), professional cooperation (17\%), increase in efficiency (14\%), and stimulation of communication (6\%). When asked about their opinion on the willingness of their organization to change, the majority (79\%) answered positively and only $21 \%$ replied in the negative about their organization.

Riggs (2001) discussed the assessment of leadership pertaining to libraries, particularly academic libraries. His definitions of organizational culture and leadership were similar to Schein's. Apart from the two mentioned by Schein, values also figured in Riggs' overview of leadership styles and trends displayed among department heads and directors of libraries. Values pertain to equitable services and access to information, and are rightfully presented as the core elements of the profession's code of ethics by the American Library Association (2008).

Kaarst-Brown, Nicholson, Von Dran and Stanton (2004) asserted that there were characteristics of organizational cultures in information-based organizations, such as the library, that led to increased collaboration, collegiality and organizational effectiveness. They investigated whether organizational culture could be leveraged as a strategic resource and asset to attract staff, and created an assessment method. The study applied the Competing Values Framework to four types of libraries: academic, public, small institutional and emerging libraries. They found that as far as academic libraries were concerned, the traditional hierarchical values had become obsolete and dysfunctional, and needed to be replaced by clan and/or adhocracy culture frameworks. These culture frameworks would allow academic libraries the flexibility needed in different ways and encourage innovation. 
The adhocracy culture would allow and motivate risk taking and entrepreneurship among library managers, and empower them to maintain the utility of the library.

Since culture is such an influential factor in organizational success, some have found that financial success and culture are directly proportional. Library managers would benefit by understanding more about their own institution and assess the culture. Varner (1996) used the Competing Values Framework to diagnose the culture of academic libraries in order to understand how new strategic actions could be taken. The research study profiled six organizational culture dimensions and four subcultures to suggest new action strategies. The study was conducted in the Midwestern University Library (Arizona, USA), and investigated the underlying effectiveness values of the academic library, the different organizational subcultures, areas in which to create new organizational values, and ways to create new qualitative performance measures for the academic library. The study found the existence of a mixed cultural profile in the library, with a dominance of Clan and Hierarchy culture types. However, the study also found that there are subcultures that exist in the various departments within the library.

Shepstone and Lyn (2008) carried out a study to diagnose the organizational culture of the library at the University of Saskatchewan in 2006 using the Competing Values Framework. The results showed that the overall culture profile of the librarians had a high score for Market culture, and the preferred culture profile showed a shift to both Adhocracy and Clan culture.

Awan and Mahmood (2009) conducted a study to explore the leadership style, organizational culture and job commitment of library employees among the universities in the Punjab province and Islamabad in Pakistan. The results showed that the employees were not aware of and sensitive to the relationship between the three factors and their work. With regard to organizational culture, they chose the McDonald and Gandz (1992) model with four culture types based on the fit with environment, strategies and values: i) Adaptability culture, ii) Achievement culture, iii) Clan culture, and iv) Bureaucratic culture. The study found that 93\% of the Chief Librarians were "Task Oriented" or "Autocratic" in their style of functioning, and only 7\% of the Chief Librarians came under the category of "People Oriented” leadership style. With regard to organizational culture and employee's commitment towards their work, the result showed significant relationship between them, with Achievement culture obtaining an average score of 4 on a 5-point Likert scale, Bureaucratic culture having an average score of 3.47, Adaptability culture an average score of 3.50, and Clan culture 3.83.

Kamenskaya (2010) analyzed the problems in the formation of organizational culture and internal communications within libraries, and proposed solutions to transforming the library employees' traditional functions, so as to become more effective and result-oriented.

Kumaresan and Swarooprani (2013) studied the relationship between organizational culture and knowledge management in the higher education libraries in Qatar. The study found a mixed culture type in higher education libraries in Qatar, with a moderate dominance of Clan culture, and that Clan and Market cultures promote Knowledge Management in the higher education libraries of Qatar.

\section{METHOD}

An online questionnaire comprising demographic questions and the Organizational Culture Assessment Instrument (OCAI) was implemented on the Web-based Internet survey website kwiksurveys.com, and sent to all the participants in March 2015. The list of licensed 
universities and colleges were taken from the UAE Ministry of Higher Education website (http://www.caa.ae/caa/desktopmodules/institutions.aspx), and 425 employees from 60 higher education libraries, whose details were available on their library website, were chosen as the sample and an e-mail with the link to the questionnaire was sent to them. A total of 284 responses were received from 39 libraries; out of which 263 were used for the analysis at a return rate of $62 \%$. The remaining 21 responses were not used because they were incomplete and hence dropped.

The Organizational Culture Assessment Instrument (OCAI) has four descriptive statements under each of the six items; each statement represents one of the four culture types representing each of the quadrants in the framework. To answer, the respondents need to divide 100 points among the four alternative statements for each item depending on the extent to which each alternative is similar to their library (Cameron \& Quinn, 2011). Nonetheless, the sum of all the four statements under each item should be exactly 100. A higher number of points should be given to the statement that is most similar to one's library and a lower number of points to that statement that is less similar or entirely irrelevant. Points can vary from 0 to 100 depending on the assessment of the level of similarity of the statements to one's library.

Scoring the OCAI requires simple arithmetic calculations. The first step is to compute an average score for the A alternatives (representing Clan culture) in the "Now" column. This is also done for the $\mathrm{B}, \mathrm{C}$ and $\mathrm{D}$ questions. The procedure is repeated for the "Preferred" column. The average scores for each alternative A, B, C and D are plotted along the diagonal lines in the four quadrants in the forms:

1. The score for the A alternative represents the Clan culture, and is plotted on the diagonal line extending upward in the top left quadrant of the form.

2. The score for the B alternative represents the Adhocracy culture, and is plotted on the diagonal line extending upward in the upper-right quadrant.

3. The score for the $\mathrm{C}$ alternative represents the Market culture, and is plotted on the diagonal line extending downward into the bottom-right quadrant.

4. The score for the D alternative represents the Hierarchy culture, and is plotted on the diagonal line extending downward into the bottom-left quadrant.

Once the scores have been plotted in each quadrant, they are connected to form a foursided figure to represent an organizational culture profile of the library. The same is repeated with the values for the preferred culture types and are plotted together to draw a comparison between the existing and preferred culture types. The profile identifies the dominant culture that is prevalent in the higher education libraries in the UAE. The culture profile may be carried out individually for each library, or carried out for a group of libraries to derive the average culture profile (Cameron \& Quinn, 2011).

\section{RESULTS}

The quadrant in which the scores are the highest indicates the culture that is emphasized in the representing library. It identifies the basic assumptions, styles and values that predominate within the library. The strength of the culture is determined by the scores awarded to each culture and how far the figure stretches in one quadrant.

Table 1 presents the demographic information of the respondents. More than half of the respondents (62\%) were men and 38\% were women. Almost half of them (48\%) were in the age group of $40-49$. Most of the respondents were expatriates at $85 \%$. More than two-thirds of the respondents (72\%) have a Master's degree as their highest degree. 
Table 1. Demographic profile of the respondents

\begin{tabular}{|c|c|c|c|}
\hline Category & Options & Frequency $(n=263)$ & Percentage \\
\hline \multirow{2}{*}{ Gender } & Female & 100 & 38 \\
\hline & Male & 163 & 62 \\
\hline \multirow{5}{*}{ Age } & 30 or less & 18 & 7 \\
\hline & $31-39$ & 81 & 31 \\
\hline & $40-49$ & 126 & 48 \\
\hline & $50-59$ & 29 & 11 \\
\hline & $60+$ & 9 & 3 \\
\hline \multirow{2}{*}{ Residency } & Nationals & 39 & 15 \\
\hline & Expatriates & 224 & 85 \\
\hline \multirow{5}{*}{ Education } & High School Diploma & 3 & 1 \\
\hline & Associate’s degree & 13 & 5 \\
\hline & Bachelor's degree & 46 & 17 \\
\hline & Master's degree & 189 & 72 \\
\hline & Doctorate degree & 12 & 5 \\
\hline
\end{tabular}

Table 2. Employment related factors of the respondents

\begin{tabular}{|c|c|c|c|}
\hline Category & Options & Frequency $(n=263)$ & Percentage \\
\hline \multirow{5}{*}{ Hierarchy } & Top Management & 15 & 6 \\
\hline & Senior Management & 28 & 11 \\
\hline & Middle Management & 124 & 47 \\
\hline & Technical Staff & 76 & 29 \\
\hline & Support Staff & 20 & 8 \\
\hline \multirow{4}{*}{ Total Experience } & 5 years or less & 26 & 10 \\
\hline & $6-15$ years & 129 & 49 \\
\hline & $16-24$ years & 90 & 34 \\
\hline & 25 years \& above & 18 & 7 \\
\hline \multirow{4}{*}{ Position Tenure } & 1 year or less & 24 & 9 \\
\hline & $2-3$ years & 53 & 20 \\
\hline & $3-4$ years & 102 & 39 \\
\hline & 5 years \& above & 84 & 32 \\
\hline
\end{tabular}

Table 2 shows the results of the employment related factors of the respondents. A majority of the respondents (47\%) were from middle management, and nearly half (49\%) have an overall work experience of $6-15$ years. $39 \%$ of them have been working in the current position for 3-4 years.

The calculated averages are grouped in Table 3 according to different groups under which the culture profiles of the higher education libraries in the UAE are analyzed. The values for each of the groups are plotted in the quadrants separately. The current and preferred 
Table 3. Average culture profile of higher education libraries

\begin{tabular}{|c|c|c|c|c|c|c|}
\hline & Group & Scope & $\begin{array}{l}\text { Clan } \\
\text { (A) }\end{array}$ & $\begin{array}{l}\text { Adhocracy } \\
\text { (B) }\end{array}$ & $\begin{array}{l}\text { Market } \\
\text { (C) }\end{array}$ & $\begin{array}{l}\text { Hierarchy } \\
\text { (D) }\end{array}$ \\
\hline \multirow[t]{2}{*}{1} & \multirow[t]{2}{*}{ UAE $(n=263)$} & Current & 37 & 34 & 14 & 14 \\
\hline & & Preferred & 55 & 38 & 7 & 2 \\
\hline \multirow[t]{2}{*}{2} & \multirow{2}{*}{$\begin{array}{l}\text { Public Universities } \\
(\mathrm{n}=113)\end{array}$} & Current & 31 & 31 & 18 & 19 \\
\hline & & Preferred & 55 & 37 & 6 & 2 \\
\hline \multirow[t]{2}{*}{3} & \multirow{2}{*}{$\begin{array}{l}\text { Private Universities } \\
(\mathrm{n}=150)\end{array}$} & Current & 42 & 36 & 11 & 10 \\
\hline & & Preferred & 55 & 38 & 7 & 2 \\
\hline \multirow[t]{2}{*}{4} & \multirow{2}{*}{$\begin{array}{l}\text { Abu Dhabi } \\
(\mathrm{n}=65)\end{array}$} & Current & 35 & 32 & 16 & 16 \\
\hline & & Preferred & 55 & 38 & 7 & 1 \\
\hline \multirow[t]{2}{*}{5} & \multirow{2}{*}{$\begin{array}{l}\text { Dubai } \\
(\mathrm{n}=70)\end{array}$} & Current & 40 & 35 & 12 & 12 \\
\hline & & Preferred & 55 & 37 & 7 & 2 \\
\hline \multirow[t]{2}{*}{6} & \multirow{2}{*}{$\begin{array}{l}\text { Sharjah } \\
(n=63)\end{array}$} & Current & 31 & 29 & 19 & 19 \\
\hline & & Preferred & 51 & 38 & 8 & 4 \\
\hline \multirow[t]{2}{*}{7} & \multirow{2}{*}{$\begin{array}{l}\text { Ajman } \\
(\mathrm{n}=30)\end{array}$} & Current & 44 & 40 & 10 & 5 \\
\hline & & Preferred & 60 & 39 & 9 & 0 \\
\hline \multirow[t]{2}{*}{8} & \multirow{2}{*}{$\begin{array}{l}\text { Fujairah } \\
(n=20)\end{array}$} & Current & 35 & 36 & 15 & 14 \\
\hline & & Preferred & 58 & 38 & 5 & 1 \\
\hline \multirow[t]{2}{*}{9} & \multirow{2}{*}{$\begin{array}{l}\text { Ras Al Khaimah } \\
(\mathrm{n}=15)\end{array}$} & Current & 41 & 36 & 12 & 10 \\
\hline & & Preferred & 56 & 37 & 5 & 1 \\
\hline
\end{tabular}

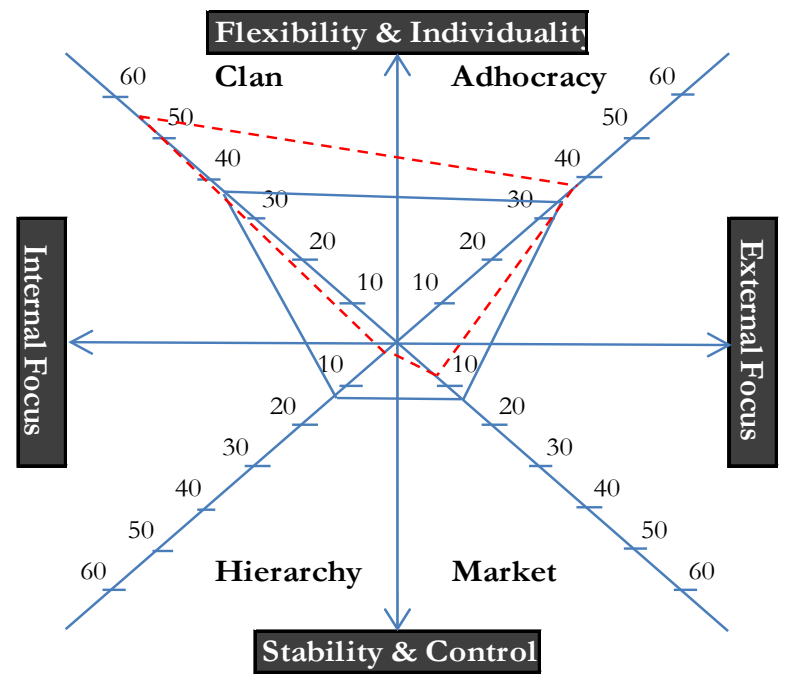

Figure 2. Average culture profile of higher education libraries in the UAE

values for each group are plotted in one figure and distinguished by the color and pattern of the lines. The blue and continuous line represents the current culture profile, and the red, and dotted lines represent the preferred culture profiles within the group. The average values in 
the first group UAE combine the responses received from all the higher education libraries in the UAE. The values in the second and third groups are between the state-funded public higher education libraries and private higher education libraries. The remaining is grouped under each for the seven Emirates in the UAE.

From Figure 2, Clan and Adhocracy cultures seem to dominate existing organizational cultures in higher education libraries, with average values of 37 and 34. Market and Hierarchy cultures are also present with an average value of 14 each. Therefore we can conclude that Clan and Adhocracy cultures are predominant in the higher education libraries in UAE, along with the presence of less significant Market and Hierarchy cultures. However, what is interesting is the preferred culture by the respondents, which is represented by red dotted lines in Figure 2. It stretches high in the Clan quadrant which indicates that the Clan culture is preferred over Adhocracy. Again, Market and Hierarchy cultures are less significant. It can also be inferred that respondents want their libraries to be even friendlier places to work in, with commitment, human development and freedom, and with less control and routine.

\section{Comparison of Culture Profile Between Public and Private Universities}

Figures 3 and 4 present the culture profiles of libraries from public and private universities. The desired or preferred culture by the respondents in both the groups, represented by red dotted line, look quite similar to each other, which means that the aspirations of respondents from both these groups were similar. They wanted greater Clan dominance and almost no Hierarchy and Market cultures. However, the existing culture differed between public universities and private ones. The public universities demonstrated a mixed culture type, with the presence of all the cultures, while the private universities demonstrated a greater dominance of Clan and Adhocracy cultures.

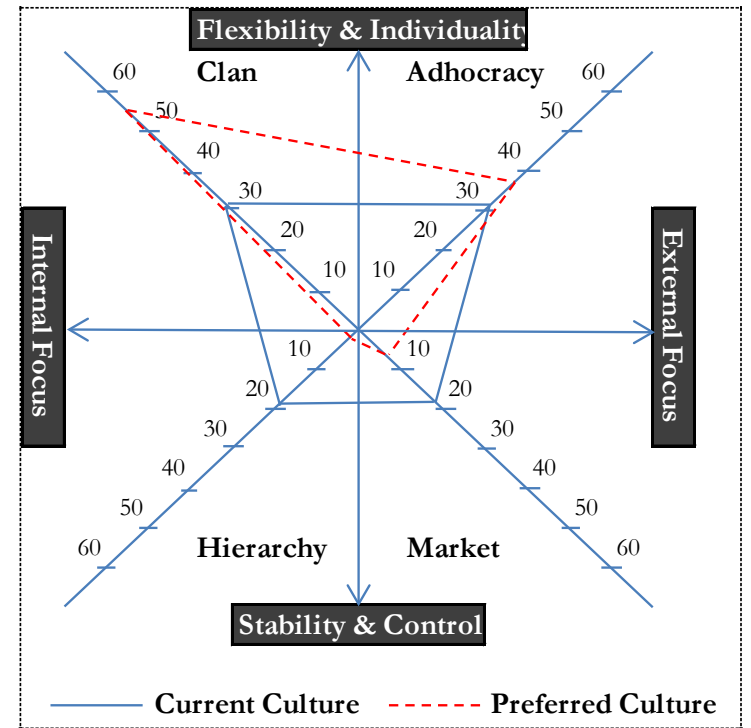

Figure 3. Culture profile of higher education libraries in public universities/colleges

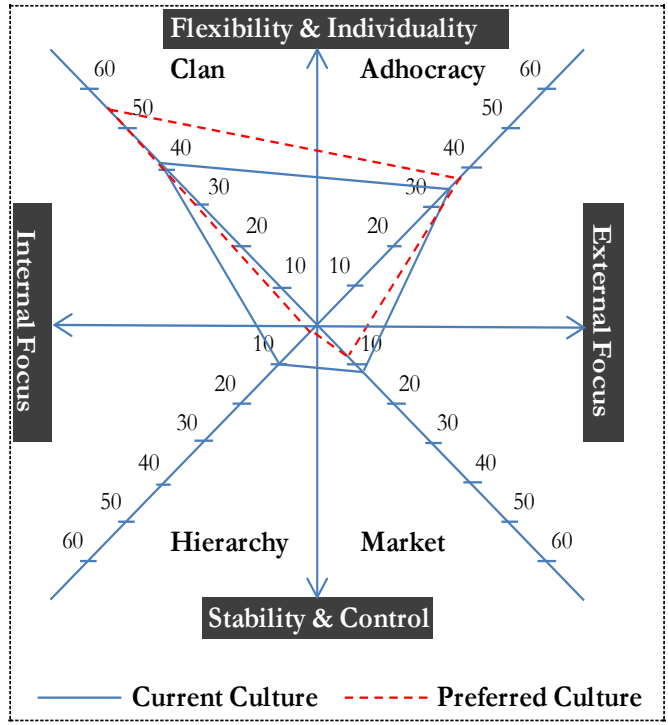

Figure 4. Culture profile of higher education libraries in private universities/colleges 


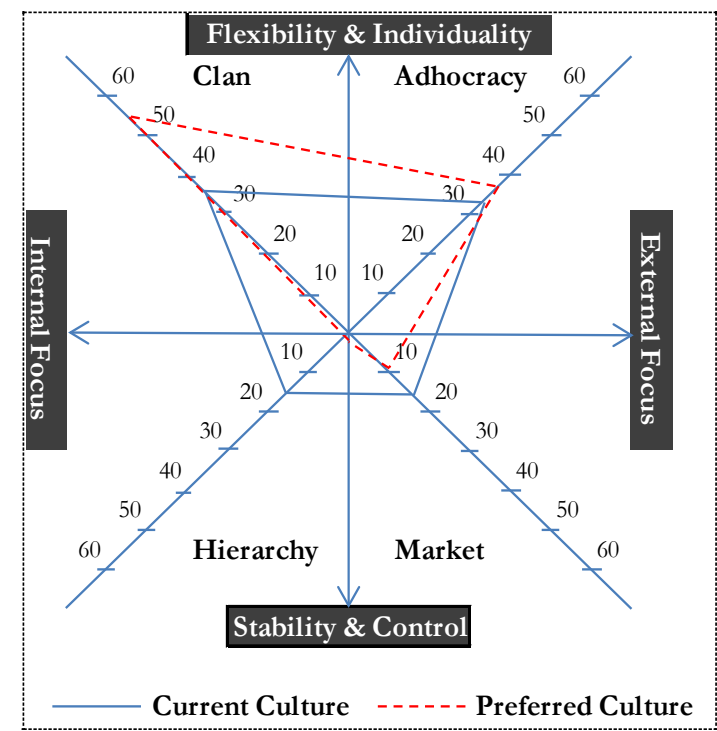

Figure 5. Culture profile in Abu Dhabi

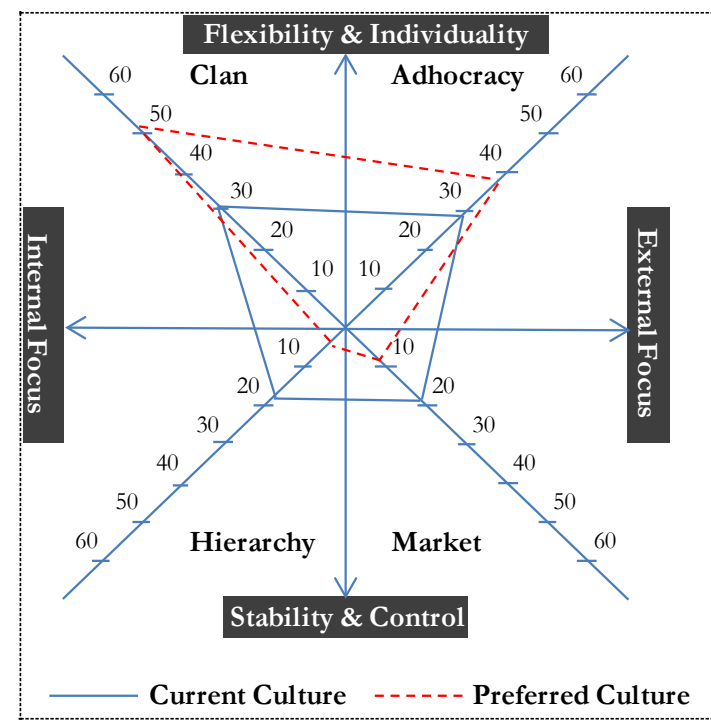

Figure 7. Culture profile in Sharjah

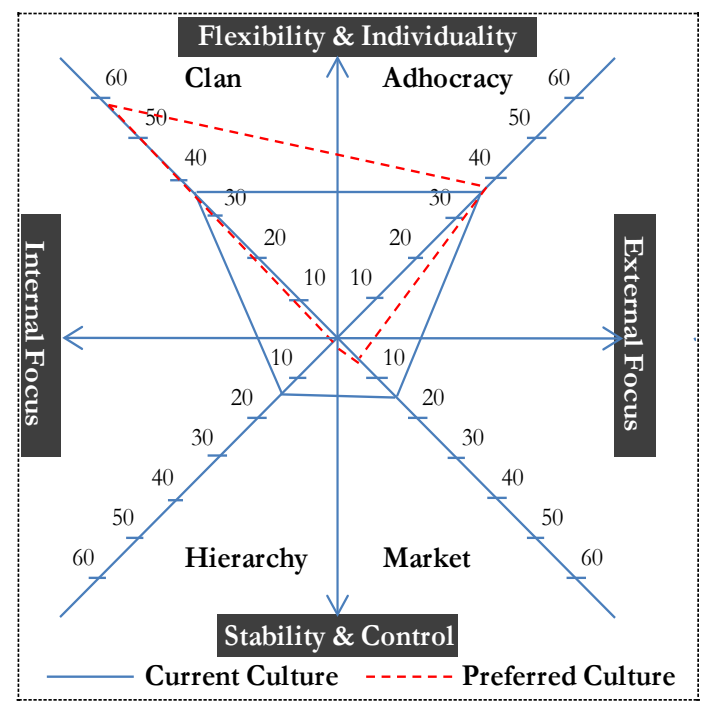

Figure 9. Culture profile in Fujairah

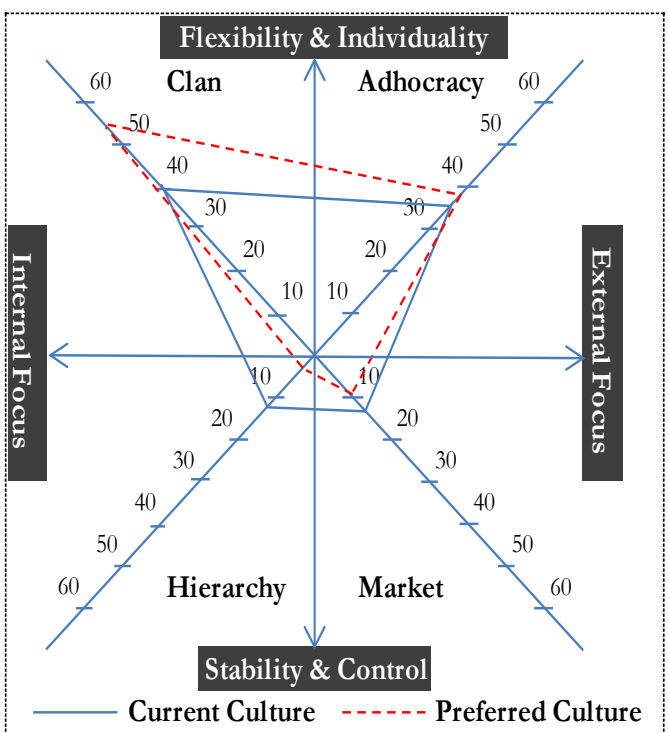

Figure 6. Culture profile in Dubai

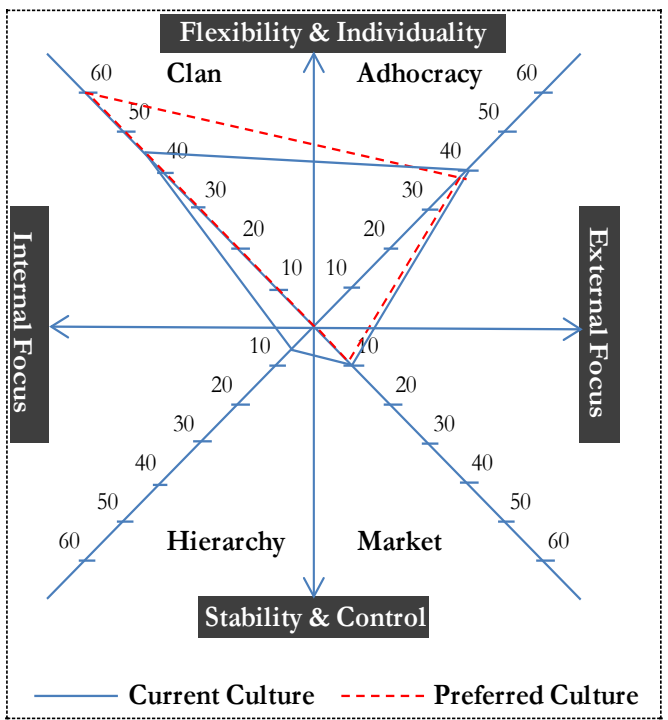

Figure 8. Culture profile in Ajman

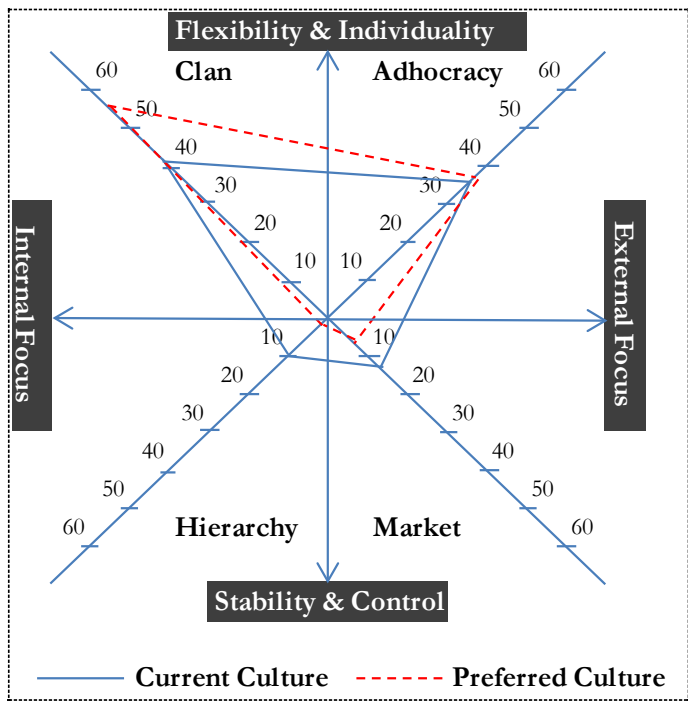

Figure 10. Ras Al Khaimah 


\section{Comparison of Culture Profile Between the Emirates}

Figures 5 to 10 present the average culture profile of the current and preferred cultures from the six Emirates from which the responses were received. Note the preferred culture profile, represented in red dotted lines. Respondents from all the Emirates indicated a preference for a dominant Clan and Adhocracy culture without a Hierarchy culture and a minimal Market culture. This means that employees preferred a friendlier workplace with commitment, human development and more freedom at work. They did not want any organizational control over their work and were not willing to focus only on the routine. However, the current culture in the universities and institutions in Abu Dhabi, Dubai, Sharjah and Fujairah was a mixed one with a dominance of Clan and Adhocracy cultures; but the universities and institutions in Ajman and Ras Al Khaimah had a greater dominance of Clan and Adhocracy cultures compared to Market and Hierarchy cultures. This means that employees from these two Emirates enjoy less organizational control over their work and more freedom to try new things and innovate.

\section{DISCUSSION}

The results of the study suggest that almost all the higher education libraries in the UAE have predominantly Clan and Adhocracy cultures. Nevertheless, Market and Hierarchy cultures vary in significance between the libraries from the different Emirates. It is also interesting that there is a significant presence of Clan and Adhocracy cultures in almost all the higher education libraries throughout the country. It suggests that employees in higher education libraries in the UAE consider their workplace to be a friendlier place of work where people help each other and the employees are well taken care of. It also shows that with greater freedom at work, employees have the liberty to innovate and experiment. Although there is a presence of Market and Adhocracy cultures in all the higher education libraries, the libraries in Sharjah and Abu Dhabi are more controlled and goal- oriented, compared to libraries in the other Emirates. Libraries in Ajman seem to have less organizational control since the Hierarchy averages are very small. It is also interesting to compare the culture types of higher education libraries in public versus private universities and institutions. Libraries in the public universities and institutions seem have a mixed culture with almost all the four cultures having considerable presence with minimal difference in averages. On the other hand, the libraries in private universities and institutions seem to have less control, are friendlier workplaces and enjoy more freedom compared to their counterparts in public universities and institutions.

What is more interesting is the preferred culture in the higher education libraries in the UAE. The results suggest that employees of all the libraries in the country prefer absolute freedom at work, employee-friendly management, the ability to innovate and be creative, and having a leader who is a facilitator or a mentor. The employees also prefer to be under less control in their work. These values for the preferred culture are uniformly found in higher education libraries throughout the country.

This study was conducted at the national level, and hence the results have national implications and significance for library directors and the academia. Cameron and Quinn (2011) asserted that organizations with Clan and/or Adhocracy' cultures were the most successful and innovative and had a strategic advantage over others. Employees in these organizations are highly motivated and cooperative. Innovation, creativity and new ideas are the hallmark of organizations with Adhocracy cultures. Communication flows freely between employees and employee welfare is at the heart of these organizations. Libraries in which 
these two cultures are predominant, are more likely to be successful and progressive in fulfilling their mission, vision and goals. They would probably be more innovative in their services and facilities.

Library directors need to consider culture in the strategic planning of libraries and all management initiatives. If library directors understand their organization's culture, they can consider the degree of fit required between their library's management actions and culture. A cultural assessment of the libraries will help in articulating the mission clearly and aligning diverse intra-organizational cultures while facilitating change and organizational transformations (Kaarst-Brown, Nicholson, Von Dran \& Stanton, 2004).

\section{CONCLUSION}

Organizational culture is a crucial element for organizational effectiveness and excellent employee performance. Clan and Adhocracy cultures are the most desired and preferred cultures for the employees in higher education libraries in the UAE. Library directors and managers need to understand the values of each culture to plan new strategies. In order to bring about a change in the organizational culture, the ability to understand the existing culture and the idiosyncratic elements of culture are critical. Since culture constitutes the greatest influence of many dimensions of human behaviour, understanding and diagnosing them are paramount. The Competing Values Framework (CVF) is therefore a useful tool for the analysis and diagnosis of organizational values, as it reveals how an academic library is likely to behave when faced with challenges. The CVF allows the library leadership to evaluate strategies from the perspective of the organizational culture in order to design the most effective means to attain the desired results.

\section{REFERENCES}

American Library Association. (2008). Code of ethics of the American Library Association. Retrieved from http://www.ala.org/advocacy/proethics/codeofethics/codeethics

Awan, M. R., \& Mahmood, K. (2009). Relationship among leadership style, organizational culture and employee commitment in university libraries. Library Management, 34(4/5), 253-266.

Cameron, K. S., \& Quinn, R. E. (2006). Diagnosing and changing organizational culture: Based on the competing values framework (Rev. ed.). San Francisco, CA: Jossey-Bass Publishers.

Cameron, K. S., \& Quinn, R. E. (2011). Diagnosing and changing organizational culture: Based on the Competing Values Framework (3rd ed.). San Francisco, CA: Jossey-Bass Publishing Company Inc.

Durkheim, E. (2014). The rules of sociological method, and selected texts on sociology and its method (W.D. Halls, Trans.). New York: The Free Press. (Original work published 1901)

Festinger, L. A. (1957). A theory of cognitive dissonance. Stanford, CA: Stanford University Press.

Geertz, C. (1973). The interpretation of cultures: Selected essays. New York: Basic Books.

Goodenough, W. H. (1971). Culture, language, and society. Reading, MA: Addison-Wesley Modular Publications.

Grant, D., \& Michelson, G. (2005). Guest editorial: Discourse and organizational change. Journal of Organizational Change Management, 18(1), 6-15.

Kaarst-Brown, M. L., Nicholson, S., Von Dran, G. M., \& Stanton, J. M. (2004). Organizational culture of libraries as a strategic resource. Library Trends, 53(1), 33-53.

Kamenskaya, I. N. (2010). Organizational culture as a basis for the competitiveness of a library. Scientific and Technical Information Processing, 38(1), 27-33. 
Kumaresan, S. C., \& Swarooprani, B. S. (2013). Measurement of organizational culture of higher educational libraries in Qatar using the competing values framework. Journal of the Madras School of Social Work, 7(2), 93-111.

Lakos, A., \& Phipps, S. (2004). Creating a culture of assessment: A catalyst for organizational change. Libraries and Academy, 4(3), 345-361.

Linn, M. (2008). Organizational culture: An important factor to consider. The Bottom Line, 2(3), 88-93.

McDonald, P., \& Gandz, J. (1992). Getting value from shared values. Organizational Dynamics, 20(3), 64-77.

Oberg, D. (2009). Libraries in school: Essential contexts for studying organizational change and culture. Library Trends, 58(1), 9-25.

Panda, K. C., \& Mandal, M. (2006). Corporate culture in libraries and information centers to promote “knowledge-based business" in IT era. Library Management, 27(6/7), 446459.

Porumbeanu, O. (2010). Implementing knowledge management in Romanian academic libraries: Identifying the elements that characterize their organizational culture. Journal of Academic Librarianship, 36(6), 549-552.

Quinn, R. E., \& Rohrbaugh, J. (1983). A spatial model of effectiveness criteria: Towards a Competing Values approach to organizational analysis. Management Science, 29(3), 363-377.

Ravasi, D., \& Schultz, M. (2006). Responding to organizational identity threats: Exploring the role of organizational culture. Academy of Management Journal, 49(3), 433-458.

Riggs, D. E. (2001). The crisis and opportunities in library leadership. Journal of Library Administration, 32(3/4), 5-17.

Schein, E. H. (1985). Organizational culture and leadership. San Francisco, CA: Jossey-Bass Publishers.

Shepstone, C., \& Lyn, C. (2008). Transforming the academic library: Creating an organizational culture that fosters staff success. The Journal of Academic Librarianship, 34(4), 358-368.

Varner, C. H. (1996). An examination of an academic library culture using Competing Values Framework (Doctoral dissertation, Illinois State University, 1996). Retrieved from ProQuest dissertation database. 